\title{
Study of urinary uric acid and creatinine ratio as a marker for neonatal asphyxia
}

\author{
Saranya S.R ${ }^{1}$, Rajmohan. $T^{2 *}$ \\ ${ }^{1,2}$ Assistant Professor, Dept. of Paediatrics, Thanjavur Medical College, Tamil Nadu, India
}

*Corresponding Author: Rajmohan. T

Email: rajmohandr@gmail.com

\begin{abstract}
Introduction and Objectives: Perinatal asphyxia is a common neonatal problem at times devastating because of its potential for causing permanent damage and even death of the newborn. In the absence of perinatal records, it is difficult to retrospectively diagnose perinatal asphyxia. The Apgar score describes the wellness of the newborn immediately after birth and when properly applied is a tool for standard assessment. The Apgar score does not predict neonatal mortality or neurological outcome. So it is inappropriate to use Apgar score alone to establish the diagnosis of asphyxia. In recent studies new biochemical markers are being evaluated for early diagnosis of asphyxia. ATP degradation products such as hypoxanthine and uric acid are valuable indicators of tissue hypoxia. In cases of continuing tissue hypoxia urinary excretion of uric acid is increased.

The main objective of this study was to evaluate prospectively by measuring uric acid to creatinine (Ua/Cr) ratio in early spot urine samples in diagnosing perinatal asphyxia, and to assess the relationship between urinary uric acid to creatinine ratio and severity of HIE.

Materials and Methods: This is a analytical cross sectional study done in the neonatal intensive care unit in Government Raja Mirasudar Hospital attached to Thanjavur Medical College, Thanjavur, South India form January 2016 to July 2016. Case and control group comprising of 50 asphyxiated and 50 non asphyxiated neonates were enrolled. Urine samples were collected within 24 hours of birth and urinary uric acid and creatinine levels measured. Urinary uric acid to creatinine ratio value of $>1.22$ was taken as the cut-off level.

Results: The urinary $\mathrm{Ua} / \mathrm{Cr}$ ratios were found to higher in asphyxiated neonates (2.59+-1.04) when compared with those in the controls $(0.72+-0.16, \mathrm{p}<0.001)$.
\end{abstract}

Conclusions: Urinary uric acid / creatinine ratio can be used as a marker in the diagnosis of perinatal asphyxia and staging of HIE.

Keywords: Urinary uric acid, Apgar score, Perinatal asphyxia, Creatinine.

\section{Introduction}

Birth asphyxia is estimated to account for $23 \%$ of the 4 million neonatal deaths globally. ${ }^{1}$ An estimated 1 million children who had neonatal asphyxia live with chronic neuro developmental morbidities including mental retardation, learning disabilities and cerebral palsy.

In India, 2.5-3.5 lakhs neonates die each year in the first three days of life because of birth asphyxia. ${ }^{2}$ According to national neonatal perinatal database (NNPD), asphyxia contributes to $20 \%$ of death in neonates and $8.4 \%$ of inborn babies have one minute Apgar score less than 7 and among these babies $1.4 \%$ suffer from hypoxic ischemic encephalopathy(HIE). ${ }^{2}$

Neonatal asphyxia is one of the leading causes of neonatal mortality in developing countries. 3-13\% of infants with cerebral palsy show evidence of intrapartum asphyxia.

The signs of perinatal asphyxia injury are non-specific and overlap with other illness. It is difficult to diagnose perinatal asphyxia retrospectively without perinatal records. Dr Apgar described the lack of proper systemic evaluation of newborn and further therapeutic intervention based on initial evaluation. Dr Apgar in her research paper published in 1953 was obviously disturbed by the lack of specificity in resuscitation. ${ }^{3}$

Hypoxia and hypo perfusion both contribute to asphyxia impairing tissue gas exchange resulting in tissue acidosis.

Birth asphyxia is defined as the failure to initiate and sustain breathing at birth." by WHO. ${ }^{4}$
An Apgar score at 1 minute of 0-3 defines severe birth asphyxia and 4-7 defines moderate asphyxia according to International classification of diseases (ICD 10). ${ }^{5}$

Apgar score in individual cases do not appear to correlate with outcome and hence are frequently interpreted incorrectly for long term prognosis. ${ }^{6}$

There is poor correlation between cord blood acidosis and depression of Apgar score. Severe fetal acidosis (PH $<7)$ occurs in 2.5 per 1000 neonates representing intrapartum compromise severe enough to cause organ dysfunction but only minority of neurological complications. ${ }^{7}$

In recent studies new biochemical parameters are being evaluated for early diagnosis of asphyxia. Uric acid is the end product of purine metabolism in humans. ${ }^{8}$ During reoxygenation and reperfusion after asphyxia and ischemia, hypoxanthine accumulated in both circulating blood and tissue is oxidized to uric acid. ${ }^{9}$

Since urinary creatinine can be used as the reference substrate in a spot urine sample, an increased uric acid to creatinine ration may be an absolute indicator of severity of tissue hypoxia in patients with intact renal functions. ${ }^{10}$

The ratio of urinary uric acid to creatinine helps in rapidly recognizing asphyxia and assessing its severity. Though numerous indicators for asphyxia are available, no single indicator has been found to be effective in predicting subsequent morbidity. Although many bio chemical indicators such as hypoxanthine, lactate, neuron specific enolase, brain iso enzyme of creatinine phosphokinase are reported, they are most useful for the purpose of research and still remain unavailable in most clinical services. ${ }^{11}$ 


\section{Materials and Methods Place of Study}

Government Raja Mirasudhar Hospital attached to Thanjavur Medical College, Thanjavur, South India.

\section{Period of Study}

January 2016 to July 2016

Study Design

Analytical cross sectional study.

\section{Sample Size}

Case and control group comprising of 50 asphyxiated and 50 non asphyxiated neonates respectively.

\section{Inclusion Criteria}

50 term neonates, appropriate for gestational age with following criteria were included

The neonates will be identified if at least three of the following are present

A. Intrapartum signs of fetal distress, as indicated by nonreassuring NST on continuous electronic fetal monitoring and/ or by thick meconium stained amniotic fluid.

B. Apgar score of less than 7 at one minute

C. Resuscitation with $>1$ minute of positive pressure ventilation before starting spontaneous respiration

D. Umbilical artery blood gas $\mathrm{PH}<7.2$

E. Mild, moderate o $r$ severe HIE as defined by Sarnat and Sarnat staging (1976)

\section{Exclusion Criteria}

Neonates with congenital malformations, congenital infections, metabolic disorders and mothers on antiepileptics, drug abuse, Mgso4, opioids within 4 hours prior to delivery.

\section{Investigations Done}

Urine samples were collected in the first 24 hours of life by catheterization or by attachment of urine collection bags. Urine uric acid and creatinine in the same urine sample was estimated.

Uric acid concentration was determined with auto analyser by spectro photo metric uricase method. Creatinine concentration was estimated in the same instrument by jeffes test.

\section{Statistical Method}

Descriptive statistical analysis has been carried out in the study. The correlation co efficient was used to establish the correlation between uric acid / creatinine ratio and stages of HIE. Statistical significance was defined at $\mathrm{P}$ values of < 0.01 .

\section{Results}

Table 1: Demographic and perinatal characteristics

\begin{tabular}{|l|c|c|}
\hline Characteristics & $\begin{array}{c}\text { Asphyxiated } \\
\text { neonates }\end{array}$ & $\begin{array}{c}\text { Healthy } \\
\text { neonates }\end{array}$ \\
\hline Birth weight & $2.88+-0.39$ & $2.83+-0.37$ \\
\hline Male/Female & $28 / 22$ & $29 / 21$ \\
\hline Vaginal Delivery & 35 & 48 \\
\hline LSCS & 15 & 2 \\
\hline Primi/Multi & $16 / 24$ & $22 / 28$ \\
\hline
\end{tabular}

50 cases and 50 controls comprised of asphyxiated and non-asphyxiated neonates respectively. Among asphyxiated neonates $40(80 \%)$ were in gestational age of 37-40 weeks, $10(20 \%)$ were in the gestational age of $40-42$ weeks. In control group all 50 neonates were between 37-40 weeks.

There were no significant differences between two groups with regard to weight, gestational age and parity

The mean weight in case group was 2.88+-0.39 and in control group was $2.83+-0.37$. Birthweight distribution is statistically similar with $\mathrm{p}=0.285$

Proportion of primi and multi gravid mothers are statistically similar with $\mathrm{p}=0.423$

In our study the incidence of caesarean section and instrumental delivery are significantly more in cases (34\%) compared to control (4\%) with $\mathrm{p}=0.001$. the incidence of non-reassuring NST is significantly more in cases $(86 \%)$ against control with $\mathrm{p}<0.001$

Among the 50 neonates in case group, 18(36\%) neonates had an Apgar score of $<7$ at $5 \mathrm{~min}$ and 32 (64\%) had Apgar score above 7. Also 9(18\%) neonates had Apgar score of $<7$ at $10 \mathrm{~min}$ and $41(82 \%)$ had scores above 7 . All the 50 neonates in the control group had an apgar score $>7$

Table 2: Correlation of urinary uric acid and creatinine ratio (UUA/CR) with HIE status

\begin{tabular}{|l|c|c|c|c|}
\hline & Not in HIE & Stage I & Stage II & Stage III \\
\hline Neonates & 10 & 18 & 17 & 5 \\
\hline UUA/CR & $1.28+-0.3$ & $2.66+-0.70$ & $2.79+-0.74$ & $4.29+-0.46$ \\
\hline Range & $0.78-2.65$ & $1.62-3.48$ & $1.11-3.92$ & $3.52-4.74$ \\
\hline
\end{tabular}

The incidence of HIE among neonates is shown in Table II. Among the 50 neonates, $18(36 \% 0$ had stage I HIE, 17 (34\%) had stage II HIE and $5(10 \%)$ had severe HIE.

The correlation of urinary uric acid and creatinine ratio with HIE status is shown in Table II. Uua/ $\mathrm{Cr}$ ratio is significantly higher in study group compared to control group with $\mathrm{p}<0.001$

In our study urinary uric acid / creatinine value of $>1.22$ has $86 \%$ sensitivity, $92 \%$ specificity and an accuracy of $89 \%$ in diagnosing asphyxia among term neonates.

\section{Discussion}

Perinatal asphyxia is a common neonatal condition contributing significantly to neonatal morbidity and mortality.

It is a devastating condition because of its potential to cause permanent damage and even death of the neonate.

The signs of asphyxia injuries are non specific and may overlap with other illnesses. Due to limitations, the Apgar scores alone cannot be used as an useful tool for the evaluation of asphyxia in neonates.

Various factors especially prematurity has an effect on it as a result of which it may not predict mortality and morbidity definitely. In the absence of perinatal records, it is difficult to diagnose neonatal asphyxia retrospectively. We cannot precisely distinguish the false positively diagnosed from the true positive asphyxiated neonates. The role of 
various biochemical markers for diagnosing asphyxia is inadequate and controversial. ${ }^{13}$

Although several biochemical indicators such as lactate, hypoxanthine, brain isoenzyme of creatinine phosphokinase, neuron specific enolase, excitatory amino acids and erythropoietin are reported, they are mostly useful in research and not available in most clinical services. ${ }^{11}$

In our study an attempt was made to ascertain whether $\mathrm{Uua} / \mathrm{Cr}$ ratio can distinguish an asphyxiated from nonasphyxiated term neonate. These tests are readily available in most centers.

Our study showed significant increase in $\mathrm{Ua} / \mathrm{Cr}$ ratio in early urine samples from asphyxiated full term neonates and the study revealed positive correlation between $\mathrm{Ua} / \mathrm{Cr}$ ratio and severity of HIE.

$\mathrm{Uua} / \mathrm{Cr}$ ratio was significantly elevated in asphyxiated neonates when compared with control $(p<0.001)$ in Reem Mohamed and Dina E Abd study ${ }^{14}$ which is similar to the finding in our study.

The higher $\mathrm{Ua} / \mathrm{Cr}$ ratio was found in severe $\mathrm{HIE}$ in our study which is similar to Reem Mahamoud and Dina E Abd study. ${ }^{14}$

Table 3: Comparison of Uua/Cr ratio between other studies

\begin{tabular}{|l|c|c|c|}
\hline $\begin{array}{l}\text { Reem Mohamoud } \\
\text { and Dina EI Abd }\end{array}$ & $2.9+-0.73$ & $0.72+-0.35$ & $<0.001$ \\
\hline Basu et al & $3.1+-1.3$ & $0.96+-0.54$ & $<0.001$ \\
\hline Bader et al & $2.06+-1.12$ & $0.64+-0.48$ & $<0.001$ \\
\hline Present Study & $2.59+-1.04$ & $0.72+-0.16$ & $<0.001$ \\
\hline
\end{tabular}

In a study done by Basu et $\mathrm{al}^{13}$ and Badar et $\mathrm{al}^{15}$ the urinary $\mathrm{Ua} / \mathrm{Cr}$ ratio was significantly higher in cases than controls which is similar to our study.

Ciler Erdag and vitinel also reported that the mean uric acid and creatinine ratio within 24 hours of birth was more in asphyxiated than non-asphyxiated neonates. ${ }^{16}$

$\mathrm{Ua} / \mathrm{Cr}$ ratio allows rapid recognisation of asphyxia and assessment of its severity so it can be a good, simple screening test for early assessment of neonatal asphyxia. Furthermore there is a correlation between Uua/Cr ratio and the severity of encephalopathy. However this ratio does not provide further prognostic information that must be obtained by other methods.

\section{Conflict of Interest: None.}

\section{References}

1. Lawn JE, Cousens S, Zupan J. Lancet Neonatal Survival Steering Team. 4 million neonatal deaths: When? Where? Why? Lancet 2005;365(9462):891-900.

2. NNPD network. National Neonatal Perinatal Database - report for the year 2002-2003. NNF NNPD network. New Delhi: 2005.

3. APGAR V. A proposal for a new method of evaluations of the newborn infant. Curr Res Anesth Analag 1953;32:260-7.

4. Agarwal R, Jain A, Deorari AK. Post-resuscitation management of asphyxiated neonates. Indian J Pediatr 2008; 75:175-180

5. Tooly J. Perinatal asphyxia and Hypoxic-ischemic encephalopathy. Perinatal. Neonatal medicine. In: McIntosh N,
Helms P, Smyth R Logan S, editors. Forfar and Arneils's textbook of Pediatrics. $7^{\text {th }}$ edition. Philadelphia: Chruchill Livingstone, an imprint of Elsevier Ltd;2008. P.204-7.

6. AAPCFN. The Apgar score. Pediatr.2006;117;1444.

7. Levene M. Perinatal asphyxia and Hypoxic-ischemic encephalopathy. In: Mclntosh N, Helms P, Smyth R, editors. Forfar and Arneill's textbook of Pediatrics. $6^{\text {th }}$ edition. Philadelphia: Chruchill Livingstone, an imprint of Elseveir Ltd; 2003. p.197-203

8. Wilcox WD. Abnormal serum uric acid levels in children. $J$ Pediatr 1996;128:731-41.

9. Rieselbach RE and Steele TH: Influence of the kidney upon urate homeostasis in health and disease. Am J Med 1974;56:665-9.

10. Nagdy N, Komen W, Ko HK. Early biochemical indicators of hypoxic ischemic encephalopathy after birth asphyxia. Pediatr Res 2001;49(4):502-6.

11. Shah S, Tracy M and Smyth J. Postnatal lactate as an early predictor of short term outcome after intrapartum asphyxia. $J$ Perinatal 2004;24(1):16-20.

12. Tekgul H, Yalaz M, Kutukculer N. Value of biochemical markers for outcome in term infants with asphyxia. Pediatrr Neurol 2004;31(5):326-32.

13. Reem Mahmoud and Dina El Abd. Pediatric and Chemical Pathology Departments Faculty of Medicine, Cairo University. Urinary Uric Acid/Creatinine Ratio in Term Infants with Perinatal Asphyxia.

14. Bader D, Gozal D, Weinger-Abend M, Berger A. neonatal urinary uric acid and creatinine ratio as additional marker of perinatal asphyxia. Eur J Pediatr 1995;154:747-9.

15. Ciler Erdag G, Vitrinel A. Can Urinary Uric acid and creatinine ratio be used as an additional marker for neonatal asphyxia? Int Pediatr 2004;19:219.

How to cite this article: Saranya SR, Rajmohan T. Study of urinary uric acid and creatinine ratio as a marker for neonatal asphyxia. Int $J$ Med Paediatr Oncol 2019;5(2):66-8. 